\title{
Reflexões sobre a quem servem o agricultor e o educador na perspectiva da educação do campo
}

\section{Reflections on whom the farmer and educator serves from the perspective of countryside education}

\author{
Marisa Dal Ongaro \\ Mestre em Geografia - Prof ${ }^{a}$ Educação Infantil - Agudo/RS, Brasil \\ marisa.curso@hotmail.com \\ Gerson Jonas Schirmer \\ Dr. em Geografia. Prof. UFSM-CS, Cachoeira do Sul/RS, Brasil \\ geogersonsonjs@gmail.com
}

\begin{abstract}
Resumo
No campo, há uma amplitude de saberes que são revividos e reinventados, permitindo tanto ao agricultor como ao educador um contínuo processo de aperfeiçoamento que complementa a formação continuada e ampliação do conhecimento dos mesmos. Nesse sentido, este artigo, através de pesquisas bibliográficas, objetiva discutir a relevância dos trabalhos realizados pelo educador do campo e do agricultor, principalmente o agricultor familiar, para a sociedade atual. Percebe-se que o educador tem um papel fundamental na busca de uma autonomia do agricultor familiar ao mesmo tempo em que pode servir de instrumento de controle destes pelo Estado. É de suma importancia a formação continuada e a discussão da realidade dos educandos para que não ocorra uma alienação destes, causada pela submissão dos educadores e agricultores frente ao sistema capitalista que visa subjugar e controlar essa parcela da sociedade de acordo com seus interesses. Defende-se que o educador deve, através da práxis, resistir ao sistema e construir em união com a comunidade novos conhecimentos na busca de uma educação significativa, que traga uma identidade ao agricultor familiar.
\end{abstract}

Palavras-chave: Agricultor Familiar; Educador do Campo; Educação do Campo; Sistema Capitalista.

\begin{abstract}
In the field, there is a breadth of knowledge that is revived and reinvented, allowing both the farmer and the educator a continuous process of improvement that complements the continued formation and expansion of their knowledge. In this sense, this article, through bibliographical research, aims to discuss the relevance of the work carried out by the field educator and the farmer, especially the family farmer, for the current society. It is perceived that the educator has a fundamental role in the search for the autonomy of the family farmer while being can serve as an instrument of their control by the State. It is of paramount importance the continued formation and the discussion of the reality of the students so that there is no alienation of these, caused by the submission of educators and farmers to the capitalist system that aims to subjugate and control this part of society according to their interests. It is argued that the educator must, through praxis, resist the system and build new knowledge in union with the community in the search for a meaningful education that brings an identity to the family farmer.
\end{abstract}

Keywords: Family farmer; Countryside educator; Countryside education; Capitalism. 


\section{INTRODUÇÃ̃O}

Busca-se neste texto retratar os sujeitos de uma classe trabalhadora, que possuem uma vinculação com organizações e movimentos sociais do campo, especificamente ligada à agricultura familiar, que se assumem como uma identidade camponesa e que consequentemente são fruto de um processo de luta e resistência pelo reconhecimento enquanto classe camponesa ${ }^{1}$. Além de uma reivindicação pela transformação social, inicialmente batalham por reconhecimento e utilizam a história como justificativa.

São sujeitos do campo, mas não são ligados ao movimento do MST, pelo fato de já possuem a terra apesar de enfrentarem dificuldades de sobreviverem e permanecerem nela. Dessa forma, buscou-se encontrar diferenças existe tentes entre os agricultores e os camponeses. Assim,

(...)o conceito de agricultura familiar está presente desde a origem do campesinato, sendo responsável por explicar que a família, ao mesmo tempo em que é proprietária dos meios de produção, assume o trabalho no estabelecimento produtivo. Desta feita o camponês só pode ser agricultor familiar (FELICIO, p.17, 2006).

Entende-se que o conceito de camponês e agricultura familiar são muito similares e para o seu entendimento há necessidade de uma análise mais aprofundada. Ainda, de acordo com Ribeiro:

(...) as ideologias tentando camuflar o passado histórico da construção do modo de produção da agricultura camponesa, mudando o nome para agricultura familiar, faz esquecer o surgimento da luta desses trabalhadores ao longo da história e de certa forma procura adequar ao modo capitalista, porém esses trabalhadores não sobreviveram no modo capitalista, porque eles surgiram exatamente para resistir a esse sistema ( RIBEIRO, p.2, 2007).

Ainda é preciso salientar que de acordo com a lei $\mathrm{n}^{\circ} 11.326$, que estabeleceu as Diretrizes para a Formulação da Política Nacional da Agricultura Familiar e Empreendimentos Familiares Rurais a expressão agricultura familiar distingue-se da empresa capitalista. Nesse sentido,

A oficialização da expressão agricultura familiar teve como objetivo estabelecer critérios para o enquadramento legal dos produtores rurais com certas características que os classificavam como agricultores familiares. Isso para obtenção, por parte desses agricultores familiares, de benefícios governamentais, sendo indiferente o fato de esses agricultores estarem em situação de subordinação perante as empresas capitalistas ou se eram reprodutores da matriz de produção e tecnológica dominante (CARVALHO \& COSTA, p.31, 2012).

Defende-se que os camponeses se destacam pela autonomia em relação a essas empresas capitalistas, ou seja, cultivo de produtos necessários para a própria alimentação e venda do excedente, mas sem o envolvimento dessas empresas. Há também, uma diferenciação e relação ao paradigma do capitalismo agrário e da questão agrária, sobre isso Felicio defende:

\footnotetext{
${ }^{1}$ Representa historicamente na luta pela permanência na terra e que tem enfrentado grandes resistências por parte da classe capitalista.
} 
Para o paradigma do capitalismo agrário a diferença entre eles está em dois aspectos: a) o camponês é sinônimo de atraso, é resquício do feudalismo, da barbárie e, por isso, tende a desaparecer com o avanço do capitalismo se transformando em agricultor familiar; b) o agricultor familiar é importante e necessário, pois, de alguma forma, ele faz parte do agronegócio. Para o paradigma da questão agrária não há diferença entre agricultor familiar e camponês, pois, ambos são assim definidos por terem a família e o trabalho familiar por característica, pois, ao mesmo tempo em que a família é proprietária dos meios de produção, assume o trabalho no estabelecimento produtivo. Contudo, o seu futuro está na superação do trabalho familiar. É preciso inventar o trabalho familiar-cooperativo e aprender a não abominar o mercado (FELICIO, p.28, 2006).

Contudo entende-se que o ser camponês não é apenas produzir os próprios alimentos, mas há toda uma história de luta para a constituição desta classe. Essa luta é pelo reconhecimento enquanto sujeitos de direito que possuem um saber e que buscam uma melhor qualidade de vida tanto economicamente como em relação ao meio ambiente alertando para os riscos presentes no cultivo da monocultura e do agronegócio.

Nesse sentido, acredita-se que o conceito de campesinato e de agricultura familiar são muito parecidos. Dessa forma, se é que pode-se dizer que há uma diferença entre eles, corroboro com Chayanov, "de acuerdo con esto podemos plantear el primer problema de nuestra investigacion: la condicion de este aparato em continuo cambio afecta la actividad econômica de una familia que maneja su propria unidad de explotacion, y si lo hace, como y hasta qué punto?" (CHAYANOV, 1974, p. 56).

Entende-se que é preciso se pensar até onde vai a exploração da família e se há indícios de trabalho assalariado. Acredita-se que se de alguma forma a agricultura familiar encontra-se mais próxima do capitalismo, o que poderia diferenciar uma (campesinato) da outra (agricultura familiar) seria a inclusão de alguma forma de trabalho assalariado. Apesar disso, percebe-se que as semelhanças superam as diferenças, ou seja, temos mais proximidades que afastamentos e os conceitos são mais no aspecto de complementariedade do que de diferenciação. Segundo Fernandes,

O campesinato também é atual e carrega em si todas as marcas do passado, sendo que suas estruturas se reproduzem no presente como o trabalho familiar e associativo e seus costumes, em especial: suas lutas. As camponesas e camponeses do MST e de Canudos praticaram e praticam lutas de re-existências para serem e sendo o que sempre foram: camponeses, sem permanecer os mesmos. Capitalismo e campesinato se renovam e se enfrentam: são duas classes produtoras de territórios a partir de distintas relações sociais. Surgem novos conceitos, como agronegócio e agricultura familiar, mas as estruturas permanecem mudando as conjunturas. Estas estruturas em movimentos nos ensinam que as múltiplas determinações não estão definidas: elas são resultados das ações que causam suas próprias transformações (FERNANDES, p.27, 2013).

Inclui-se no imaginário dos agricultores que produzir para a sua sobrevivência é uma tarefa inferiorizada, ou seja, a policultura é discriminada enquanto a monocultura é enaltecida.

Neste trabalho ressalta-se a experiência observada junto a comunidades do município de Agudo-RS, onde a grande maioria está subordinada a monocultura do fumo, apesar dos programas e projetos incentivarem o contrário. 
Nas lutas ambos possuem metas comuns, como por exemplo, reconhecimento, melhores preços para mercadorias, políticas públicas próprias, principalmente por uma educação que reflita a realidade/necessidade dessas famílias ${ }^{2}$. Nesse sentido, sobre essa educação:

Estamos no âmbito da Educação do Campo e da reflexão sobre suas práticas, entre elas a da
escola. Trata-se de um campo que se abre à produção do conhecimento em diferentes áreas,
e particularmente na área da pedagogia, ou do como conduzir processos educativos,
assumindo o movimento permanente, e às vezes contraditório, entre o particular e o
universal na construção de uma análise da realidade que nos permita trabalhar para novas
relações sociais. Nosso tempo é de urgências. Urge o tempo da luta de todos pela dignidade
roubada de cada um de nós. Mas a sabedoria camponesa nos ensina que esta luta urgente é
uma luta de resistência e persistência. É preciso trabalhar agora pensando já na próxima
safra, preservando com cuidado as sementes e prestando atenção no tempo certo de seu
plantio. (MACHADO et.al, 2008, p.07).

Demonstra-se então a preocupação com a terra, de onde é retirada a sobrevivência dos sujeitos que residem no campo. Destaca-se também a importância da formação continuada para os educadores e agricultores na perspectiva da formação de sucessores, a fim de que estes possam se apropriar dos conhecimentos e saberes históricos criados e recriados no campo. Percebe-se a união entre ideais dos agricultores e assentados, logo se os objetivos são semelhantes a luta também se torna comum, então junta-se forças e unem-se os movimentos em prol de objetivos comuns de formação para atender a essas pessoas porque o ponto de partida (necessidade, realidade é outra) e o que se quer desse sujeito também será.

Portanto, a formação, do educador do campo é um grande desafio para ele, pois além de lecionar no campo, através do estudo e da pesquisa sobre questões relacionadas ao cotidiano dos educandos, cabe a eles a buscarem soluções para as inquietudes vivenciadas por si e elos outros. Para tanto, torna-se necessário que estes estejam abertos e dispostos a aprender sobre tais inquietudes e questionamentos identificando as contradições presentes na sua educação e na dos educandos, consequentemente na dos agricultores.

Assim como o trabalhador é alienado da produção, alguns educadores também são alienados, pois não percebem que ensinando nos moldes tradicionais com os conteúdos descontextualizados estão sendo peça integrante do sistema capitalista, seguindo regras e ideologias do mesmo. O educador que não possui um ideal político para lutar e defender, que aceita todas as novas políticas públicas sem questionar ou discutir com seus alunos as consequências das mesmas, que não se preocupa com o destino dos alunos e consequentemente da população em geral, que admite ser escravizado pelo sistema e nada faz para mudar essa situação, aliena-se. Novamente viemos ressaltar que é contra essa alienação que nós nos colocamos, contudo existem exemplos

\footnotetext{
${ }^{2}$ Lutam pela Educação do campo, que apesar de ter suas origens no MST e discutir principalmente os problemas dos assentados, ambos (agricultores e assentados) possuem características semelhantes e assim, os ideias da educação do campo se adéquam as duas realidades.
} 
desses educadores alienados em todas as escolas. Dessa forma, a contradição do sistema capitalista não está apenas no processo produtivo, mas também e em especial, na escola, pois:

\begin{abstract}
Nesse processo produtivo, o trabalhador é alienado da produção, por não identificar o produto de seu trabalho como seu e desconhece a mais-valia gerada pelo seu trabalho, ou seja, não tem consciência de que é explorado. O trabalhador naturaliza o poder existente nas relações de produção e entre patrão e empregado, tornando natural a relação de "mando e obediência", valores produzidos pela sociedade capitalista. Para atingir seus objetivos e se consolidar, a primeira estratégia histórica do capitalismo foi separar o trabalho manual do trabalho intelectual, fragmentando o processo produtivo (SOUZA et al, 2008, p.24).
\end{abstract}

Compreende-se que no sistema capitalista busca-se a manutenção da condição social das pessoas através das relações vivenciadas, como estratégia de dominação. A Escola, enquanto Instituição do Estado, segue aos interesses da classe dominante e consequentemente do sistema capitalista, pois:

Assim, fragmentada, a escola também irá funcionar. Estudos realizados há décadas buscam analisar como funciona a escola na sociedade capitalista e como ela reproduz a sociedade em que está inserida. Para esta compreensão é importante ter a noção de que as relações sociais acumulam não só o capital econômico, mas também o capital cultural e social, e que a classe trabalhadora, independentemente do espaço em que estiver, sofre com as desigualdades no seu processo educativo, tendo menos acesso aos materiais didáticos e pedagógicos, aos instrumentos de escrita, aos bens culturais. Seus sujeitos são condicionados às relações sociais que mantêm sua própria condição social (SOUZA et al, 2008, p.24).

Portanto a escola, por muito tempo serviu e talvez hoje ainda sirva como mantedora do poder e de acordo com Souza (2008), “Ou, dito de outro modo, a própria escola e o ensino transformam-se em mera mercadoria com mais ou menos qualidade para quem pode pagar". Demonstra-se então, um desvelamento do ensino e da escola, qual sua função e qual seria efetivamente sua meta.

Acredita-se, no senso comum, que há uma contradição entre o pedagógico e o financeiro. Contudo, o pedagógico depende em parte do financeiro. Sabe-se que temos questões políticas, culturais ideológicas que estão ligadas ao econômico e aos meios de produção, sendo que um interfere no outro, ou seja, as questões políticas, por exemplo, interferem indiretamente nas fábricas e os empresários com seus anseios financiam e interferem nas políticas. Isso tudo afeta a condição social do agricultor que depende do econômico para sobreviver.

Percebe-se que a única forma de impedir que estejamos nas mãos de grandes empresários que comandam indiretamente nosso país é através da implementação do projeto de educação do campo, que busca através da práxis ${ }^{3}$, uma superação da prática pedagógica tradicional e através de uma educação baseada nos princípios e valores do campo produzir uma cultura diferenciada. É imprescindível entender que o educador não precisa saber passar conhecimento, mas precisa saber

\footnotetext{
${ }^{3}$ Pressupõem a transformação dos sujeitos porque as práxis não é a reprodução de práticas, mas uma reflexão a partir da realidade que se impõem na tentativa de compreender e superar os problemas e necessidades enfrentados.
} 
porque esse conhecimento é significativo. É necessária uma práxis baseada no questionamento da realidade vivenciada e do auto questionamento em busca de uma contínua aprimoração do conhecimento.

Os problemas enfrentados pela educação não encontram-se apenas no campo, porém é nele que a situação permanece mais crítica, pois até então não levava-se em consideração a realidade socioeconômica e ambiental onde cada escola do campo está inserida. A escola do campo é historicamente caracterizada como um espaço de precariedade e de descaso, especialmente pela falta de apoio das instituições governamentais e pela ausência de políticas públicas. Sobre isso, concordo com Machado:

...a realidade da educação da população do campo que, como se sabe, foi historicamente, de
um lado relegada ao descaso e até mesmo ao esquecimento e, de outro, caracterizou-se
como uma educação que teve por base programas e campanhas realizadas "para o meio
rural". Essas campanhas e programas, implementados de forma descontínua, não podem ser
caracterizados como política pública e não foram elaborados com a participação dos
sujeitos do campo, sendo feitas para eles e não com eles (MACHADO et.al, 2008, p.13).

Percebe-se que o campo só era, e infelizmente continua sendo lembrado em época de campanha eleitoral política, onde os candidatos se dirigiam até os pequenos agricultores para pedir seu voto. Apesar desses problemas, acredita-se no projeto de educação do campo que propõem uma emancipação dos sujeitos envolvidos, partindo do diálogo de saberes e da valorização dos modos de lidar com os recursos naturais (terra, água, sementes, etc). Assim, demonstra-se o esquecimento do campo e de sua importância, tanto nos modos de vida camponeses, quanto na atividade econômica, afetiva/significativa, presente na produção de alimento e rememoração de histórias passadas que constitui a atual sociedade.

Nesse sentido, segundo Borges (2012), na década de 1960 quando foi aprovado o Estatuto do Trabalhador Rural que assegurava alguns direitos ao camponês, porém faz com que a luta dos trabalhadores fosse sufocada pela ditadura militar com a aprovação da Lei 4.504/64 que criou o Estatuto da Terra. Para Matos (2003), após golpe de 1964, foi através do intermédio da Igreja Católica (Movimentos Eclesiais de Base) e outros partidos de esquerda que acontece uma reorganização dos movimentos sociais.

Cabe destacar que segundo Machado (2008) foi no $1^{\circ}$ ENERA (Encontro Nacional dos Educadores da Reforma Agrária) que surgiu a proposição de Educação no e do Campo, sendo que a I Conferência Nacional por Uma Educação Básica do Campo aconteceu em agosto de 1997, em Luziânia, Goiás. Durante a Conferência, decidiram dar continuidade à mobilização nacional a partir da realização de 23 encontros estaduais, com o objetivo de trocar experiências educacionais e analisar as dificuldades comuns. 
Contudo, o ensino que atualmente vem sendo proposto em grande parte das escolas localizadas no campo está ligado ao agronegócio, suas tecnologias e agrotóxicos. Necessita-se urgente de projetos políticos pedagógicos vinculados a reconstrução da sociedade que temos em vista da construção da sociedade sustentável. Que esse projeto possa ouvir a comunidade e que sua elaboração possa ser discutida com toda a gestão da escola. Sobre a sociedade sustentável tem-se um importante documento "A Carta da Terra", que foi retificada pela UNESCO e aprovada pela ONU em 2002:

Estamos diante de um momento crítico na história da Terra, numa época em que a humanidade deve escolher seu futuro. À medida que o mundo torna-se cada vez mais interdependente e frágil, o futuro enfrenta, ao mesmo tempo, grandes perigos e grandes promessas. (...) Devemos somar forças para gerar uma sociedade sustentável global baseada no respeito pela natureza, nos direitos humanos universais, na justiça econômica e numa cultura da paz. Para chegar a este propósito, é imperativo que nós, os povos da Terra, declaremos nossa responsabilidade uns para com os outros, com a grande comunidade da vida, e com as futuras gerações (A Carta da Terra, 2002).

O mundo encontra-se em continuo processo de degradação. Nesse sentido, o projeto de educação do campo é uma grande estratégia para discussão dos principais causadores dessa degradação, dentre elas destaca-se principalmente o agronegócio. Contudo, há necessidade de ampla participação da comunidade na construção da proposta de educação do campo entendendo esse processo como oportunidade de aprendizagem de todos porque o projeto de escola não está pronto, mas pode/deve ser construído por todos.

\section{A FINALIDADE DA ESCOLA E DO EDUCADOR}

Entende-se o campo como uma totalidade que exige que os educadores contextualizem os saberes universais com os locais e históricos. Assim, busca-se entender a importância das particularidades, pois é nelas que serão reveladas as contradições e será dado um novo sentido as especificidades e diferenças que separam a escola das famílias dos educandos. Contudo, é notável que ao passo que se desconstrói algumas barreiras outras vão sendo construídas em ritmo acelerado pelo capitalismo que possui um enorme interesse em manter as famílias de pequenos agricultores subordinadas e escravas desse sistema.

Dessa forma, quanto mais afastadas da informação e do conhecimento, maior a facilidade do sistema impregnar uma ideologia, que tem como propósito o consumismo exacerbado. Logo, é de suma importância que o educador questione essas falsas verdades vendidas pela mídia e também pala sociedade enquanto instrumento do Estado, que nos faz acreditar na necessidade de nos igualarmos esteticamente.

Para Caldart (2009), realmente as pessoas que moram no campo são diferentes. Essa diferença é encontrada em relação a gênero, etnia, religião, modos de produzir e viver, um diferente 
modo de olhar o mundo e de absorver os problemas. Porém tem-se uma identidade comum: "somos um só povo; somos a parte do povo brasileiro que vive no campo e que historicamente tem sido vítima da opressão e da discriminação, que é econômica, política e cultural (CALDART, 2009, p.153)"'.

As pessoas que vivem no campo têm um jeito peculiar de ser. Para isso os conteúdos devem ser selecionados de acordo com o significado que tem para a comunidade em que a escola está inserida. De acordo com Brasil (2010):

O processo de escolarização e qualificação social e profissional tem na agricultura familiar um paradigma de educação voltado para o aprendizado de conceitos, princípios e fazeres necessários a construção de um país que tenha satisfatória qualidade de vida, educação e trabalho para os povos do campo (BRASIL, 2010, p.27).

Assim, a educação do campo visa orientar os educandos para que problematizem a sua realidade e a partir disso e do conhecimento de outras realidades (local e o global) possam olhar para si e para sua comunidade com o intuito de discutir/melhorar os problemas vivenciados no campo. Na educação é importante ter presente em todas as ações que tipo de sujeito se pretende formar e localizar a criança dentro da sociedade a qual ela pertence, de modo que ela possa entender a estrutura político-produtiva do território na qual ela se localiza e a ligação deste com os demais que formam o Município.

Um processo ativo de aprendizagem pressupõe a participação e discussão dos alunos, contudo em meio a explicações e novas perguntas, percebesse que há dificuldade do educador conseguir realizar uma escuta atenta em relação a todas as contribuições dos alunos. Assim, desenvolve-se uma prática automática onde responde-se e discute-se o que se consegue ouvir, deixando alguns alunos sem resposta. Apesar disso, é importante destacar que essa é uma pratica que possibilita o estudo tanto do conteúdo selecionado pelo educador para a aula, quanto os conteúdos relacionados a ele e de interesse dos alunos.

Ainda, destaca-se que no campo, é preciso que se oportunize um ensino relacionado com as atividades que as crianças vivenciam no cotidiano. Assim, busca-se uma escola com os ideais que se assemelham com a "Escola Plural" de Arroyo: "Tenho sido perguntado por que o nome Escola Plural. A escolha do nome tenta incorporar a procura pedagógica de uma docência aberta à pluralidade de saberes e de aprendizagens, à pluralidade de dimensões do desenvolvimento humano, da formação dos educandos e dos educadores" (ARROYO, 2002, p.71).

Um dos eixos dessa Escola Plural era a sensibilidade com a totalidade da formação humana, que é construída na atuação coletiva, nos movimentos e que busca uma abertura nos conteúdos da docência. Entende-se que o educador não deve restringir-se apenas a área pela qual é 
formado, mas deve atuar correlacionando as diferentes realidades dos educandos refletidas em sua cultura.

O autor anteriormente citado, desenvolve então uma crítica em relação a esse sistema escolar que tem perdido sua pluralidade de funções socioculturais. Essa crítica é fortalecida com a lei $n^{\circ}$ 9394/96 que tem como contribuição a incorporação de uma concepção ampliada da educação, destacando em seu $1^{\mathrm{o}}$ artigo que: "A educação abrange os processos formativos que se desenvolvem na vida familiar, na convivência humana, no trabalho, nas instituições de ensino e pesquisa, nos movimentos sociais e organizações da sociedade civil e nas manifestações culturais" (LDB 9394/96).

Considerando que a finalidade da educação é desenvolver a plenitude do educando, tornase papel do educador ampliar as dimensões de seu ensino, de forma que seja possível englobar os saberes do campo. Dessa forma, é indispensável uma reflexão sobre a luta dos movimentos sociais e consequentemente sobre os conflitos existentes na sociedade é resultado da própria existência das classes sociais e seus interesses antagônicos. Cabe então salientar a diferença entre ser professor e ser educador: "Enquanto se mantém a concepção de professor associada à prática de repassar o que está escrito nos livros, dificilmente vamos conseguir avanços rumo a uma educação transformadora, associada a um projeto popular de sociedade, com vistas à superação das classes sociais" (FERNANDES et al., 2008, p.20).

Para tanto, há uma barreira que precisa ser superada, a formação dos educadores do campo que em alguns casos é muito semelhante ou a mesma que dos educadores urbanos. Torna-se de suma relevância questionar a viabilidade de ter uma mesma formação para culturas, territórios e interesses tão diferentes. Além disso, segundo Fernandes:

Infelizmente, constatou-se que os professores das redes públicas pesquisadas são formados
e controlados nos parâmetros do sistema capitalista e encontram dificuldades para perceber
que poderia ser diferente. Observou-se, também, que as mesmas sofreram e sofrem todo o
tipo de influências possíveis dos pacotes urbano-agrícolas decorrentes do sistema
capitalista. O que chamamos de "pacotes urbano-agrícolas" podem ser compreendidos
dentro das estratégias atuais do modo de produção capitalista para a agricultura,
principalmente do agronegócio e, nas escolas, podem chegar através de propagandas,
seminários, livros didáticos, etc. (...) Sendo assim, não são movidos pela busca de
transformação da sociedade, deixando-se levar pela maré neoliberal da educação, ou
mesmo por interesses pessoais (FERNANDES et al., 2008, p.19).

Outro ponto fundamental é a elucidação das contradições existentes entre a teoria e a prática, uma vez que esta é a principal ferramenta do capitalismo. Na explicitação das contradições há a possibilidade de compreensão do papel de cada sujeito na sociedade, de que futuro se busca e se está construindo e de como poderia se libertar desse sistema no qual Estado, como mantenedor dos interesses das classes dominante se fortalece. Na prática ele não oferece 
atendimento as necessidades mínimas e asseguradas em lei, como saúde, segurança e entretenimento. Ainda, para Fernandes:

\begin{abstract}
A realidade nos mostra que muitos educadores(as) apenas passam pela Universidade, pois o que mais interessa a eles é o diploma ou título, não a qualidade de sua formação (...) tais cursos estão comprometidos com qual classe social? E, em decorrência, qual a qualidade de tais cursos? Não dá para culpar os professores porque estaríamos nos desviando do núcleo da questão, que é a sociedade baseada na apropriação privada da terra, dos meios de subsistência e do produto do trabalho. Não interessa às oligarquias dominantes que a classe trabalhadora aprenda a pensar... É aí que se pode encontrar a raiz da 'Pedagogia do Improviso', que oculta a "desqualificação da educação pública" destinada às camadas populares (FERNANDES et al., 2008, p. 20).
\end{abstract}

O professor é vítima da própria formação, uma vez que aceitam colegas que apenas estão no curso fisicamente, não contribuem e não se interessam pela formação, sendo estes mesmos colegas que irão representar a profissão no mercado de trabalho e que contribuirão para a desvalorização do educador. Também são vítimas das políticas públicas que são impostas verticalmente sem condições física/materiais para tanto e sem a formação continuada para atender as demandas e novas implementações nas quais tem-se submetidos. Além disso, são vítimas do próprio sistema que através de baixíssimos salários obriga a aumentar a demanda de trabalho o que acarreta em uma educação de baixa qualidade. Nesse sentido Fernandes afirma que:

$\mathrm{Na}$ maioria das vezes, os profissionais da educação tornam-se vítimas da própria formação pedagógica e, nas suas práticas, acabam por reproduzir novas vítimas, muitas por não terem oportunidade de buscar novas alternativas, até por razões econômicas, tendo em vista os baixos salários dos professores estaduais e municipais; outros, porque se acomodam ou têm medo do novo. Sendo assim, acabam por continuar reproduzindo práticas incorporadas pela formação deficiente que receberam e deixam de buscar novas fontes de conhecimento e qualificação (FRENANDES et al., 2008, p.21).

Revela-se então a necessidade da formação continuada, que por vezes pode acontecer através da própria reflexão de um discurso ou mesmo de uma leitura. Percebe-se que a formação é para além do título, mas tem-se a oportunidade de refletir sobre práticas e relacionar com a teoria, que nos motiva/ensina a ser educador. Sobre esse assunto Freire afirma:

A consciência é essa misteriosa e contraditória capacidade que tem o homem de distanciarse das coisas para fazê-las presentes, imediatamente presentes. É a presença que tem o poder de presentificar: não é representação, mas condição de apresentação. É um comportar-se do homem frente ao meio que o envolve, transformando-o em mundo humano. Absorvido pelo meio natural, responde a estímulos; e o coito de suas respostas mede-se por sua maior ou menor adaptação; naturaliza-se. Despegado de seu meio vital, por virtude da consciência, enfrenta as coisas objetivando-as e enfrenta-se com elas, que deixam de ser simples estímulos, para se tornarem desafios (FREIRE, 1987, p.07).

Esse conhecimento é construído durante o tempo e reconstruído a partir de novos saberes que a ele vão sendo acrescentados, demonstra-se assim que o tempo também pode ser um agente de formação continuada. O mesmo acontece com as famílias de pequenos agricultores, onde a partir da prática, do empírico, das experiências que produziram e também das que não produziram que se 
constitui o conhecimento do saber plantar, lidar com a terra e dela retirar o alimento, sabedoria e até sustento. Sobre esse assunto, acredita-se que o agricultor assim como o educador possui um saber ligado à prática, uma vez que,

(...) existem coisas que se aprendem com a prática e que, entretanto, não são sabidas por aqueles que "não tem prática". Assim, um vendedor ou um professor de uma escola primária reagirá, "por instinto", de maneira pertinente, em tal ou qual situação, o que não saberia fazer quem não tivesse a prática de venda ou de ensino. Isso é verdade, mas, ainda, deve ser interpretado. Quem "tem prática" vive em um mundo onde percebe indícios que outros não veriam, dispõem de pontos de referência e de um leque de respostas dos quais outros estariam desprovidos. A prática não é cega, ela tem ferramentas e organiza seu mundo; ela supõe, e produz, o aprender (CHARLOT, 2000, p.63).

Dessa forma, cabe questionar o que, efetivamente, o educando precisa saber, considerando que ele já possui a palavra ${ }^{4}$, mas que pode e deve construir novas palavras em busca de que este possa tornar-se cada vez mais atuante e crítico no território em que reside e nos demais territórios que estão interligados a sua comunidade. Nesse sentido, a educação é fundamentada em uma concepção dialética, não sendo um produto, mas obra, inspiração e trabalho de um processo social. Ainda, a palavra a ser discutida precisa questionar a atual fragmentação imposta pelo poder e pelas contradições que fazem parte da instituição de ensino, consequentemente também fazendo parte de toda a sociedade.

\section{A RELAÇÃO DA IDEOLOGIA COM A FORMAÇÃO DOS EDUCADORES E DO AGRICULTOR}

A educação do campo discutida anteriormente como estratégia de reação as ideologias, busca na formação dos educadores e consequentemente agricultores a reflexão/construção de indivíduos que possuem uma palavra em defesa/valorização de si e da sua comunidade. Segundo Borges (2012):

As funções produtivas levaram os seres humanos a não se encontrarem mais em condições semelhantes na sociedade, e sim em condições de inferioridade e superioridade. Essas diferenças eram justificadas pela visão sagrada, ou seja, o amo era sagrado, designado por Deus, e o escravo era inferior, por isso deveria obedecer à ordem social, sem questiona-lo (BORGES, 2012, p. 84).

Nessa citação percebe-se uma ideologia imposta pela classe superior (amo) em relação a classe inferior(escravo). Essa ideologia sustentou-se em valores cristãos para dar um aspecto verídico a sua imponência e justificar suas atrocidades. Conforme (Marx e Engels, 2001, p. 31), "A burguesia controla cada vez mais a dispersão dos meios de produção, da propriedade e da população. Aglomerou a população, centralizou os meios de produção e concentrou a propriedade em poucas mãos".

\footnotetext{
${ }^{4}$ A palavra se remete ao termo utilizado por Paulo Freire no livro Pedagogia do Oprimido. Considera-se que todos tem a palavra, porém é necessário que se acrescentem novas palavras, novos conhecimentos. Parte-se da ideia de que vai sendo constituindo o arcabouço de palavras ao longo de da vida, a partir das experiências vividas e dos conhecimentos construídos.
} 
Assim o capitalismo, para Borges (2012), faz com que o trabalhador deixe de ser dono de sua produção (terra) e passe a ser dono apenas da sua força de trabalho. Fica claro então o opressor, ao qual todos são submetidos e que a muito tenta encontrar uma estratégia de libertação. Essa libertação, no âmbito da agricultura camponesa, se dá través da informação, do conhecimento, do desenvolvimento da autonomia e de um olhar crítico ao que os cercam e que constitui sua própria realidade.

Nesse sentido revela-se a importância do educador na comunidade, pois ele é quem detém a informação e o conhecimento para apontar caminhos e soluções para as contradições vivenciadas pela sociedade. No entanto, normalmente são iludidos pela ótica do capital. Contudo, quando remete-se aos educadores, uma das tarefas mais difíceis a ser superada é o medo da liberdade ${ }^{5}$, o medo do desconhecido e logo estes se mantem estacionados nas mesmas práticas que os antigos professores já desenvolviam, por serem fáceis, por serem conhecidas e por não oferecerem riscos de errar ou de serem questionadas.

É possível perceber que a maioria dos educadores sabem que o conteúdo deveria ser contextualizado, porém não efetivam esta proposição em sua prática pedagógica. Essa é uma contradição, evidenciada na prática da escola, contudo cabe a nós pesquisadores compreendermos o porquê deles não fazerem, já que se sabem que seria o correto. Seria medo da liberdade, seria falta de aprofundamento teórico ou seria falta de reflexão sobre a relevância da contextualização?

Ao estudar as contradições, compreende-se que não existe uma verdade pronta, acabada e inquestionável, portanto, não há uma resposta, ou seja, um paradigma, ${ }^{6}$ mas existem conhecimentos que se aproximam mais da verdade em um determinado momento histórico/temporal. Assim, de acordo com Cirne-Lima as contradições possibilitam um questionamento sobre esta verdade.

A razão una e universal que perpasse as múltiplas sub-razões, o sistema que abarque e abranja os múltiplos subsistemas, isso não existe. Isso é contraditório, explode e se desmancha em cacos. Razão e sistema, não; temos apenas cacos e fragmentos. É por isso que o estudo da contradição hoje mais do que nunca ficou importante. É preciso, reconstruir o grande mosaico de sentido do mundo, de sua história e de suas vidas. (...) Para chegarmos lá, precisamos, antes de mais nada, tentar decifrar o problema de contradição. Pois tudo começou com ela: a razão, pensada como una, era contraditória, o sistema, projetado como expressão da razão una, desmanchou-se em suas contradições (CIRNE-LIMA, 1993, p.10).

A partir desta citação é possível repensar o sistema capitalista, os paradigmas criados e recriados por ele para que as pessoas trabalhassem e consumissem, de tal forma que esse pudesse, com o tempo, tornar-se cada vez mais forte. Contudo, seus paradigmas também se revelaram contraditórios, os pequenos agricultores buscam direitos, liberdade e o mais importante, desejam ser vistos e reconhecidos como sujeitos de saberes históricos. Saberes estes, que movimentam e dão sentido as suas vidas. Dessa forma,

Num mundo que fica, tanto em seus problemas como em suas perspectivas de solução, mais e mais universal e globalizante, faz-se mister reencontrar a razão, una, única, oniabrangente que hoje é modesta, sim, porque se sabe jamais pronta e acabada, mas que apesar disso, está consciente de sua indispensável unidade (CIRNE-LIMA, 1993, p.10).

As contradições motivam a indignação, os agricultores buscam/pedem soluções, mas encontram-se presos ao sistema. Os problemas são evidentes: o direito de por preço ao seu produto,

\footnotetext{
${ }^{5}$ Este termo é utilizado por Paulo Freire no livro Pedagogia do Oprimido, pag. 13.

${ }^{6}$ No livro “A estrutura das Revoluções Científicas" de Thomas Kuhn, paradigma significa realizações cientificas universalmente reconhecidas, durante algum tempo.
} 
a venda do produto em casa, a valorização da classe, incentivo a diversificação da propriedade, as melhores condições de acesso a saúde, etc. Contudo, estes sentem-se fracos e desmotivados ao perceberem que a escola (instituição/território), presente dentro da sua comunidade (território), possui outros objetivos. Tem-se então uma luta de classe entre professores que representam o Estado consequentemente o sistema capitalista contra a agricultura familiar representada pelos agricultores. É uma luta também de poder, pois ambas as classes disputam o espaço e a credibilidade das crianças e adolescentes que residem naquela comunidade, o que acaba sendo uma disputa entre o campo (do agricultor) e a cidade (do professor).

\section{CONSIDERAÇÕES FINAIS}

Percebeu-se a partir das reflexões deste trabalho que a escola se tem colocado, em grande maioria das vezes como território do Estado, inserido na comunidade em oposição ao território dos agricultores. A escola, como instituição do Estado adota as políticas públicas criadas pelo mesmo que indiretamente segue ao interesse do agronegócio. $\mathrm{O}$ agricultor familiar luta para permanecer e valorizar seu território. Nesse sentido, surge a contradição, pois ambos (Estado e agricultor familiar) possuem interesses antagônicos.

No entanto, o agricultor familiar não sabe de sua força e sua importância para com o Estado e com o restante da sociedade, que na verdade depende dele. Há uma inverdade propagada pelos meios de comunicação que inverte propositalmente essa informação. Apresenta-se aqui a ideologia que é disseminada pela educação, pela cultura, pela política e pelos meios de comunicação. Esta ideologia refere-se em disseminar que para o agricultor a qualidade de vida é mantê-lo "vivo" por mais tempo e produzindo para empresas de acordo com ruralismo pedagógico.

Se no campo e na cidade não discutirmos o que temos e como queremos ou precisamos que seja a educação, esse processo irá acirrar-se. A educação do campo vem propor para o campo e a cidade essa reflexão, esse questionamento. Assim teremos a proposição da soberania alimentar, que não é só para o campo.

Contudo, o educador possui uma função muito importante, a de mostrar as oportunidades e caminhos existentes na comunidade onde a escola está inserida e tendo como fundamento teórico a palavra geradora, acredita-se que o educador deve aproveitar todos os detalhes e oportunidades para tentar contextualizar o conteúdo e com isso reforçar a identidade do agricultor familiar.

\section{REFERÊNCIAS}

ARROYO, M. G. Ofício de Mestre: imagens e auto-imagens. 1. ed. Petrópolis: Vozes, 2000. 256p.

BORGES, H. S. Educação do Campo como processo de luta por uma sociedade justa. In: GHEDIN, E. Educação do Campo: epistemologias e práticas. São Paulo: Cortez, 2012.

BRASIL. Ministério da Educação. Diretrizes Curriculares Nacionais Gerais para a Educação Básica. Brasília: MEC, 2010. 562p.

BRASIL. Coleção Cadernos Pedagógicos: Projovem Campo - Saberes da Terra. 1. ed. Brasília: Ministério da Educação, 2010. 140p. 
CAldart, R. S.; CAStagna, M. (Org.). Por uma Educação do Campo. 4. ed. Petrópolis: Vozes, 2009. 153p.

CARTA DA TERRA - Organização das Nações Unidas, 2002.

CARVALHO, I. C. M. Educação ambiental: a formação do sujeito ecológico. 2. ed. São Paulo: Cortez, 2006. 256p.

CARvalhO, H. M.; COSTA, F. A. Agricultura Camponesa. In: CAldART, R. S. (Org.). Dicionário da Educação do Campo. Rio de Janeiro: Expressão Popular, 2012. p. 259-267.

CIRNE-LIMA, C. R. V. Sobre a Contradição. 1. ed. Porto Alegre: EDIPUCRS, 1993. 60p.

CHAYANOV, A. La organización de la unidad económica campesina. 1. ed. Buenos Aires: Ediciones Nueva Vision, 1974. 342p.

CHARLOT, B. Da relação com o saber: elementos para uma teoria. 1. ed. Porto Alegre: Artes Médicas Sul, 2000. 96p.

FELICIO, M. J. A conflitualidade dos paradigmas da questão agrária e do capitalismo agrário a partir dos conceitos de agricultor familiar e de camponês. Campo-Território, Uberlândia, v. 1, n. 2, p. 14-30, 2006.

FERNANDES, B. M. Construindo um estilo de pensamento na questão agrária: o debate paradigmático e o conhecimento geográfico. 2013. 329f. Tese (Livre-docência) - Faculdade de Ciência e Tecnologia, Universidade Estadual Paulista, Presidente Prudente, 2013.

FERNANDES, A. G; SOUZA, E. A; CONTE, I. I; MAGGIONI, L; ABREU, M. V; RIBEIRO, M. A pedagogia e as práticas educativas na educação do campo. In: MACHADO, C. L. B; CAMPOS, C. S. S; PALUDO, C. Teoria e prática da educação do campo: análises de experiências. Brasília: MDA, 2008.

FREIRE, P. Pedagogia do oprimido.17 ed. Rio de Janeiro, Paz e Terra, 1987. 256p.

MACHADO, C. L. B.; CAMPOS, C. S. S.; PALUDO, C. Teoria e prática da educação do campo: análises de experiências. 1. ed. Brasília: MDA, 2008. 236p.

SOUZA, E. J.; ANDRADE, E. F.; LIMA, G. A. M.; MACHADO, C. L. B. Limites e possibilidades: um olhar sobre o projeto político pedagógico na perspectiva da educação do campo. In: MACHADO, C. L. B.; CAMPOS, C. S. S.; PALUDO, C. Teoria e prática da educação do campo: análises de experiências. Brasília: MDA, 2008. 